\title{
SISTEM PENUNJANG KEPUTUSAN PENILAIAN GURU TERBAIK PADA SD ISLAM DIAN DIDAKTIKA CINERE DENGAN MENGGUNAKAN METODE SIMPLE ADDITIVE WEIGHTING (SAW)
}

\author{
Anugrah Oktavino ${ }^{1)}$, Grace Gata ${ }^{2)}$ \\ ${ }^{1}$ Sistem Informasi, Fakultas Teknologi Informasi, Universitas Budi Luhur \\ ${ }^{1,2} \mathrm{JI}$. Raya Ciledug, Petukangan Utara, Kebayoran Lama, Jakarta Selatan 12260 \\ E-mail : oktavinoanugrah.ao@gmail.com ${ }^{1}$, grace.gata@budiluhur.ac.id ${ }^{2)}$
}

\begin{abstract}
Abstrak
Guru atau pengajar yang professional merupakan sebuah keharusan bagi sekolah dalam mekasanakan proses pendidikan yang bermutu, demikian halnya dengan SD Islam Dian Didaktika. Untuk itu, sekolah sekolah selalu mendorong peningkatan professionalitas guru dengan cara memantau kerja guru dalam mengimplementasikan tugasnya, sehingga dapat mencapai standar kompentensi yang telah ditentukan. Beberapa masalah dalam menentukan penilaian guru terbaik adalah penilaian masih manual dan kurang akurat. Hal ini membuat kepala sekolah sebagai pengambil keputusan sulit menentukan guru yang mempunyai nilai terbaik, selain itu perlu waktu lama dalam pengumpulan data, seperti form kehadiran guru dan form evaluasi kinerja guru. Dengan Metode Simple Additive Weighting (SAW) digunakan untuk menentukan penilaian guru terbaik dengan menghasilkan perankingan alternatif. Sistem penunjang keputusan pemilihan guru terbaik ini dibuat dengan MySQL sebagai database dan Browser sebagai tools. Oleh karena itu penelitian ini betujuan untuk menghasilkan sebuah sistem penunjang keputusan, dengan adanya sistem tersebut diharapkan tim personalia sebagai penilai pada SD Islam Dian Didaktika dapat terbantu dalam penilaian guru terbaik. Menghasilkan rancangan sistem penunjang keputusan penilaian guru terbaik dengan lebih mudah dan efektif pada saat melakukan penilaian guru terbaik dengan menggunakan sistem.
\end{abstract}

Kata kunci: SPK, SAW, Penilaian Kinerja Guru.

\section{PENDAHULUAN}

Guru merupakan seseorang yang berjasa dalam dunia pendidikan, karena guru adalah orang yang memberikan ilmu pengetahuan. Menurut Nawawi (2015: 280) Guru ialah orang dewasa, yang karena peranannya berkewajiban memberikan pendidikan kepada anak didik. [1] Orang tersebut mungkin berpredikat sebagai ayah atau ibu, guru, ustadz, dosen, ulama dan sebagainya. Guru merupakan unsur penting dalam kegiatan pembelajaran. Menurut Djamarah (2015: 280) Guru adalah seseorang yang memberikan ilmu pengetahuan kepada anak didik atau tenaga profesional yang dapat menjadikan murid-muridnya untuk merencanakan, menganalisis dan menyimpulkan masalah yang dihadapi. [2]

Dalam proses penilaian guru dengan kinerja terbaik di SD Islam Dian Didaktika Cinere mengalami kesulitan pada proses rekap dan pengolahan data kinerja guru yang hanya dilakukan dengan menggunakan Microsoft Excel, Microsoft Word dan belum menggunakan metode yang tepat untuk melakukan proses penilaian guru dengan kinerja terbaik. Oleh karena itu SD Islam Dian Didaktika Cinere memerlukan sistem penunjang keputusan untuk melakukan penilaian guru dengan kinerja terbaik guna meningkatkan kinerja guru untuk menjadi lebih baik lagi dalam proses belajar mengajar.

Penggunaan metode Simple Additive Weighting (SAW) adalah metode adalah metode yang sering dikenal dengan penjumlahan terbobot. Konsep dari metode tersebut untuk mencari penjumlahan terbobot dari rating kinerja pada setiap alternatif semua atribut.

Maka dari itu, tujuan peneliti membangun sebuah sistem penunjang keputusan yang dapat digunakan oleh pihak sekolah SD Islam Dian Didaktika untuk penilaian guru terbaik secara optimal dan mengimplementasi sistem pendukung keputusan dengan menggunakan metode Simple Additive Weighting (SAW) dengan perhitungan yang bobotnya telah ditentukan.

Studi literatur berupa hasil dari beberapa studi atau penelitian sebelumnya yang berkaitan dengan pembuatan aplikasi oleh beberapa sumber Seperti penelitian yang dilakukan Sabda Gunawan dalam Jurnal Pelita Informatika Budi Darma Vol. IX No. 3 / April 2015 "Sistem Pendukung Keputusan Pemilihan Guru Terbaik pada SMA Negeri 2 Kutacane dengan menggunakan Metode Simple Additive Weighting". Penelitian ini membahas tentang sistem pendukung keputusan untuk pemilihan guru terbaik pada SMA Negeri 2 Kutacane yang dari setiap pemilihan tersebut 
menghindari subyektifitas dari setiap keputusan yang dihasilkan. Tujuan penelitian ini adalah menerapkan sistem pendukung keputusan untuk membantu pihak sekolah dalam menentukan pemilihan guru terbaik.

\section{METODE PENELITIAN} yaitu:

Metode pengumpulan data yang dilakukan,

a. Observasi

Kegiatan ini dilakukan untuk mengumpulkan data dengan cara pengamatan langsung dengan halhal yang berkaitan dengan sistem penunjang keputusan penilaian guru terbaik di SD Islam Dian Didaktika.

b. Wawancara

Wawancara merupakan proses pengumpulan data dengan bertatap muka langsung dengan mengajukan pertanyaan yang berhubungan dengan penilaian guru terbaik yang dilakukan pada Tim Personalia sebagai pihak yang diberikan wewenang untuk menyelenggarakan penilaian guru terbaik. Dari wawancara tersebut, penulis juga mendapatkan dokumen yang akan digunakan dalam pengembangan sistem penunjang keputusan penilaian guru terbaik.

c. Analisa Dokumen

Analisa dokumen dilakukan untuk menganalisa dokumen berjalan agar diperoleh informasi yang sesuai dengan sistem yang akan dibuat.

d. Studi Pustaka

Kegiatan ini dilakukan dengan cara membaca jurnal atau e-book serta referensi lain yang berkaitan dengan teori penilaian guru terbaik yang telah dipublikasikan, teori Sistem Penunjang Keputusan, teori Simple Additive Weighting (SAW), dan teoriteori lainnya yang berkaitan dengan pembuatan sistem penunjang keputusan ini.

\section{HASIL DAN PEMBAHASAN}

\subsection{Profil Organisasi}

SD Islam Dian Didaktika Cinere merupakan Yayasan Dian Didaktika berdiri pada tanggal 14 Juni 1983, dan 8 bulan kemudian memiliki badan hukum dengan akte notaris R. Soerojo Wongsowidjoyo, SH No. 35 tanggal 22 Pebruari 1984. Adapun tujuan berdirinya yayasan ini, sebagaimana tercantum dalam anggaran dasarnya, yaitu "Ikut serta mengamalkan ajaran Islam serta membantu pemerintah dalam mengembangkan pendidikan/pengajaran, kesehatan, dan sosial/budaya”. Sehingga misi yayasan jelas, yaitu memberikan nuansa-nuansa Islami dalam setiap pelaksanaan usaha-usaha dan kegiatan-kegiatannya. Walaupun pada tahun 1988, azas Yayasan mengalami perubahan dengan menghapus azas Islam dan hanya berazaskan Pancasila, akan tetapi etika Islam tetap menjadi landasan bagi setiap pelaksanaan usaha-usaha dan kegiatan-kegiatan yayasan.Badan atau Dewan Pendiri Yayasan Dian Didaktika terdiri seorang Ketua dan 16 orang anggota, yaitu :

a. Visi

Pendidikan Paripurna bernafaskan Islam

b. Misi

1. Menyelenggarakan pendidikan yang menerapkan nilai-nilai ajaran Islam

2. Menyelenggarakan pendidikan yang mengembangkan kecerdasan majemuk

3. Mengembangkan pribadi sesuai dengan perkembangan zaman

4. Mengembangkan budaya santun, jujur, tenggang rasa, toleran dan memiliki kepedulian sosial yang tinggi

c. Lima Nilai Sikap Dian Didaktika

1. Religius

2. Jujur

3. Disiplin

4. Santun

5. Peduli

\subsection{Analisa Proses Bisnis Berjalan}

Activity diagram dapat digunakan untuk menentukan kebutuhan apa saja yang diperlukan dari suatu sistem (Indrajani, 2017). [3]

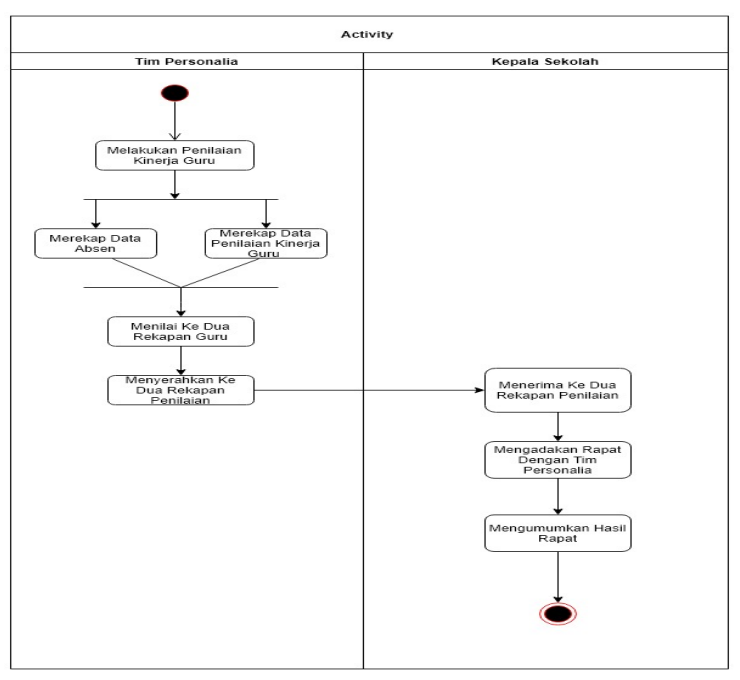

Gambar 1. Activity Diagram Berjalan

Seperti terlihat pada pada gambar 1. activity diagram berjalan penilaian guru terbaik dilakukan dengan melihat penilaian Tim Personalia menilai, merekap, dan mengisi daftar penilaian guru. Kemudian Tim Personalia menyerahkan rekapitulasi daftar penilaian kepada Kepala Sekolah. Selanjutnya, Kepala Sekolah mengadakan rapat 
dengan Tim Personalia terkait hasil penilaian yang dilakukan Tim Personalia. Dan Kepala Sekolah mengumumkan hasil rapat untuk menentukan guru terbaik.

\subsection{Analisa Masalah}

Fishbone Diagram adalah salah satu analisis yang dapat digunakan untuk memecahkan masalah. Fungsi dasar dari diagram fishbone (tulang ikan)/cause and effect(sebab dan akibat) adalah untuk mengidentifikasi dan mengorganisasi penyebab-penyebab yang mungkin timbul dari suatu efek spesifik dan kemudian memisahkan akar penyebabnya(Nugraha, 2016). [4]

Dalam menganalisa masalah-masalah yang terjadi di SD Islam Dian Didaktika Cinere dalam penilaian kinerja guru, penulis menggunakan fishbone diagram untuk mendeskripsikan penyebabpenyebab dari sebuah masalah yang terjadi.

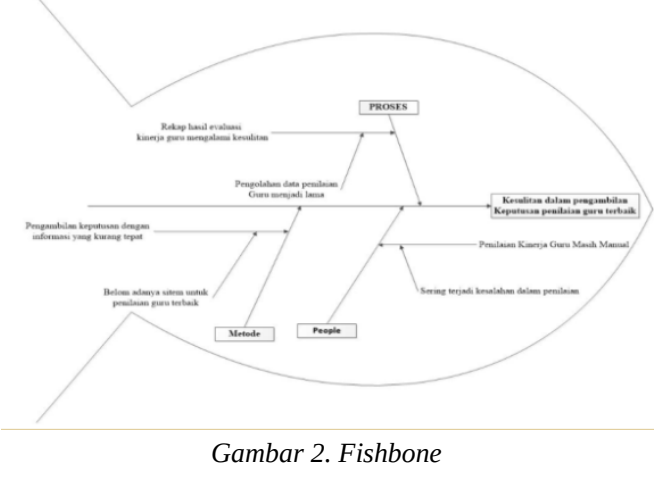

Seperti pada gambar 2. Fishbone masalah utama yang dihadapi oleh SD Islam Dian Didaktika Cinere dalam penilaian guru terbaik adalah kesulitan dalam menentukan guru terbaik, karena faktor-faktor seperti proses, metode, dan manusia. Proses, rekap hasil evaluasi kinerja guru mengalami kesulitan, sehingga pengolahan data guru menjadi lama. Metode, SD Islam Dian Didaktika Cinere tidak menggunakan metode yang dapat menentukan prioritas dari banyak kriteria yang mengakibatkan hasil kurang tepat. Manusia, dalam Penilaian kinerja guru pada SD Islam Dian Didaktika Cinere yang masih manual sehingga penilaian kurang akurat hasilnya.

\subsection{Use Case}

Use Case Diagram adalah gambaran perilaku sebuah sistem untuk mengetahui fungsi sistem apa saja yang ada didalam sistem informasi dan siapa saja yang berhak menggunakan fungsi-fungsi tersebut. Berikut ini adalah bagian use case diagram pada sistem penunjang keputusan guru terbaik pada SD Islam Dian Didaktika.
Dibawah ini terdapat 3 use case yaitu, use case master, use case transaksi, use case laporan:

a. Use Case Master

Use case master ini menggambarkan perilaku dari use case master dan actor bertugas menggunakan sistem. Digambarkan seperti dibawah ini:

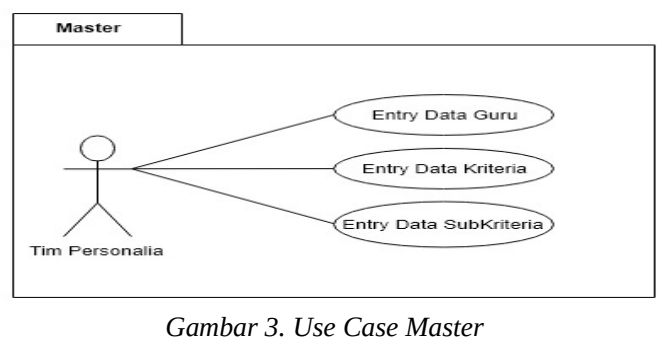

Pada gambar 3. Use Case Master menjelaskan tim personalia mengentry data guru, data kriteria, dan sub kriteria.

b. Use Case Transaksi

Use case transaksi ini menggambarkan perilaku dari actor bertugas menggunakan sistem. Digambarkan seperti dibawah ini:

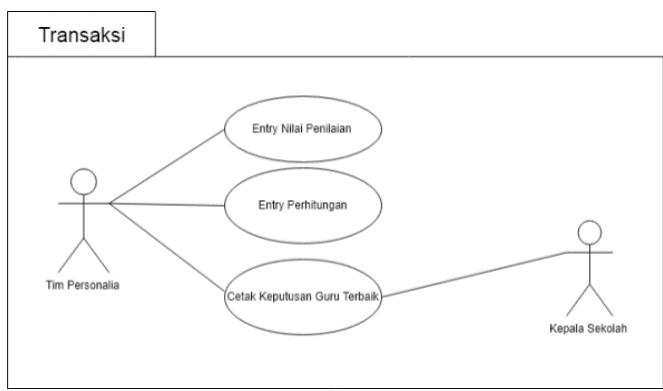

Gambar 4. Use Case Transaksi

Pada gambar 4. Use Case Transaksi menjelaskan tim personalia mengentry nilai penilaian, perhitungan, dan cetak keputusan.

c. Use Case Laporan

Use case transaksi ini menggambarkan perilaku dari actor bertugas menggunakan sistem. Digambarkan seperti dibawah ini:

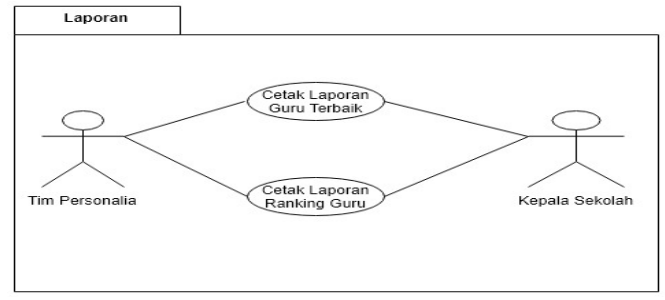

Gambar 5. Use Case Laporan

Pada gambar 5. Use Case Laporan menjelaskan tim personalia mencetak laporan guru terbaik dan laporan ranking guru, dan tim personalia 
memberikan bukti cetak laporan kepada kepala sekolah.

\subsection{Metode Simple Additive Weighting (SAW)}

Metode SAW membutuhkan proses normalisasi matriks keputusan (X) ke suatu skala yang dapat dibandingkan dengan semua rating alternatif yang ada(Abadi and Latifah, 2016). [5] Kepala sekolah dan Tim Pesonalia SD Islam Dian Didaktika Cinere telah menetapkan kriteria yang digunakan dalam pengambilan keputusan guru terbaik. Selain itu Kepala sekolah dan Tim Personalia juga telah menetapkan bobot pada setiap kriteria yang telah ditetapkan untuk menunjukan tingkat kepentingan pada setiap kriteria. Dibawah ini merupakan ketentuan bobot kriteria:

Tabel 1. Bobot Kriteria

\begin{tabular}{lll}
\hline Skor Nilai & Keterangan & Skala \\
\hline $85-100$ & Sangat Baik (SB) & 5 \\
$75-85$ & Baik (B) & 4 \\
$60-75$ & Cukup (C) & 3 \\
$45-60$ & Kurang (K) & 2 \\
$0-45$ & Kurang Sekali (KS) & 1 \\
\hline
\end{tabular}

Pada tabel 1. Bobot Kriteria menjelaskan pada skor dan skala penilaian guru terbaik di setiap kriterianya.

Dibawab ini merupakan ketentuan kriteria dan bobot kriteria:

Tabel 2. Ketentuan Kriteria dan Bobot Kriteria

\begin{tabular}{llll}
\hline Kode Kriteria & Keterangan Kriteria & Kategori & Bobot \\
\hline KN01 & Absensi & Benefit & $10 \%$ \\
KN02 & Kompetensi Pedagogik & Benefit & $20 \%$ \\
KN03 & Kompetensi Kepribadian & Benefit & $30 \%$ \\
KN04 & Kompetensi Sosial & Benefit & $20 \%$ \\
KN05 & Kompetensi Profesional & Benefit & $20 \%$ \\
& Total & & $100 \%$ \\
\hline
\end{tabular}

Pada tabel 2. Ketentuan Kriteria dan Bobot menjelaskan pada di setiap kriterianya itu menghasilkan kategori benefit dan bobotnya menjadi persen.

Dibawah ini merupakan alternatif untuk penilaian guru terbaik:

Tabel 3. Alternatif Penilaian

\begin{tabular}{ll}
\hline Kode Alternatif & Nama Guru \\
\hline 03.17 .0287 & Adhika Puspitasari, S.Pd \\
03.15 .0265 & Agni Dwi Elfahmi, S.Pd \\
03.03 .0111 & Ana Saptini, S.Pd, M.M. \\
03.97 .0051 & Badriah El Qudsy, S.Pd \\
03.04 .0124 & Ainor Kholis, S.PdI \\
\hline
\end{tabular}

Pada tabel 3. Alternatif Penilaian menjelaskan pada alternatif tersebut terdapat kode atau nomor induk pengajar dan nama guru pengajar.

a. Data Nilai Alternatif Per Sub Kriteria
Tim Personalia ditugaskan oleh Kepala sekolah untuk memberikan daftar guru yang mendapatkan nominanasi sebagai alternatif untuk menentukan guru terbaik, adapun guru yang mendapatkan nominasi tersebut adalah sebagai berikut:

Tabel 4. Nilai Alternatif Per Sub Kriteria

\begin{tabular}{|c|c|c|c|c|c|c|}
\hline \multirow{2}{*}{ Kriteria } & \multirow{2}{*}{$\begin{array}{c}\text { Sub } \\
\text { Kriteria }\end{array}$} & \multicolumn{5}{|c|}{ Alternatif } \\
\hline & & KM001 & KMO02 & KM003 & KM004 & KM005 \\
\hline Absensi & Sub 1 & 2 & 5 & 5 & 5 & 3 \\
\hline \multicolumn{2}{|c|}{ Nilai Rata- Rata } & $2: 1=2$ & $5: 1=5$ & $5: 1=5$ & $5: 1=5$ & $3: 1=3$ \\
\hline \multirow{7}{*}{ Pedagogik } & $\begin{array}{l}\text { Sub } 2 \\
\end{array}$ & 3 & 3 & 4 & 4 & 3 \\
\hline & Sub 3 & 4 & 3 & 4 & 4 & 3 \\
\hline & Sub 4 & 3 & 3 & 4 & 4 & 3 \\
\hline & Sub 5 & 4 & 3 & 3 & 4 & 3 \\
\hline & Sub 6 & 4 & 4 & 3 & 4 & 4 \\
\hline & Sub 7 & 4 & 4 & 4 & 4 & 3 \\
\hline & Sub 8 & 3 & 4 & 3 & 4 & 3 \\
\hline \multicolumn{2}{|c|}{ Nilai Rata-Rata } & $25: 7=3,5$ & $24: 7=3,4$ & $25: 7=3,5$ & $28: 7=4$ & $22: 7=3,1$ \\
\hline \multirow{3}{*}{ Kepribadian } & Sub 9 & 3 & 3 & 3 & 3 & 3 \\
\hline & Sub 10 & 3 & 3 & 3 & 3 & 3 \\
\hline & Sub 11 & 4 & 5 & 4 & 5 & 5 \\
\hline \multicolumn{2}{|c|}{ Nilai Rata-Rata } & $10: 3=3,3$ & $11: 3=3,6$ & $10: 3=3,3$ & $11: 3=3,6$ & $11: 3=3,6$ \\
\hline \multirow{2}{*}{ Sosial } & Sub 12 & 4 & 4 & 4 & 4 & 4 \\
\hline & Sub 13 & 3 & 4 & 3 & 4 & 4 \\
\hline \multicolumn{2}{|c|}{ Nilai Rata-Rata } & $7: 2=3,5$ & $8: 2=4$ & $7: 2=3,5$ & $8: 2=4$ & $8: 2=4$ \\
\hline \multirow{2}{*}{ Profesional } & Sub 14 & 4 & 4 & 4 & 4 & 4 \\
\hline & Sub 15 & 4 & 4 & 5 & 3 & 5 \\
\hline \multicolumn{2}{|c|}{ Nilai Rata-Rata } & $8: 2=4$ & $8: 2=4$ & $9: 2=4,5$ & $7: 2=3,5$ & $9: 2=4,5$ \\
\hline
\end{tabular}

Pada tabel 4. Nilai Alternatif Per subkriteria menjelaskan dari penilaian guru terbaik dirataratakan agar mendapatkan nilai untuk perhitungan normalisasi.

b. Nilai Rata-Rata Per Sub Kriteria

Berikut ini akan disajikan berupa daftar nilai alternatif per sub kriteria yang telah ditentukan oleh kepala sekolah:

Tabel 5. Nilai Rata-Rata Per Sub Kriteria

\begin{tabular}{|c|c|c|c|c|c|c|}
\hline \multirow{2}{*}{ Kriteria } & \multirow{2}{*}{$\begin{array}{l}\text { Sub } \\
\text { Kríeria }\end{array}$} & \multicolumn{5}{|c|}{ A.lternatif } \\
\hline & & KMOD 1 & KMOO2 & KMOO3 & KMOO 4 & KMOO5 \\
\hline Absensi & Sub 1 & 2 & 5 & 5 & 5 & 3 \\
\hline \multirow{7}{*}{ Pe dagogik } & sub 2 & 3 & 3 & 4 & 4 & 3 \\
\hline & Sub 3 & 4 & 3 & 4 & 4 & 3 \\
\hline & Sub 4 & 3 & 3 & 4 & 4 & 3 \\
\hline & Sub 5 & 4 & 3 & 3 & 4 & 3 \\
\hline & Sub of & 4 & 4 & 3 & 4 & 4 \\
\hline & Siub 7 & 4 & 4 & 4 & 4 & 3 \\
\hline & Sub 8 & 3 & 3 & 3 & 4 & 3 \\
\hline \multirow{3}{*}{ Kepribaclian } & Sub 9 & 3 & 3 & 3 & 3 & 3 \\
\hline & Sub 10 & 3 & 3 & 3 & 3 & 3 \\
\hline & Sub 11 & 4 & 5 & 4 & 5 & 5 \\
\hline \multirow{2}{*}{ Susial } & Sub 12 & 4 & 4 & 4 & 4 & 4 \\
\hline & Sub 13 & 3 & 4 & 3 & 4 & 4 \\
\hline \multirow{2}{*}{ Profesiona1 } & Sulb 14 & 4 & 4 & 4 & 4 & 4 \\
\hline & Sub 15 & 4 & 4 & 5 & 3 & 5 \\
\hline
\end{tabular}

Pada table 5. Nilai rata-rata per subkriteria menjelaskan dari penilaian dari rata-rata nilai alternatif sub kriteria.

c. Normalisasi

Normalisasi data menjadi matriks $\mathbf{r}$ untuk menghitung nilai masing-masih kriteria dan menentukan hasil kriteria tersebut menguntungkan (benefit) atau biaya (cost) dengan rumus normalisasi sebagai berikut:

$$
r_{i j}=\left\{\begin{array}{ll}
\frac{x_{i j}}{\operatorname{Max}_{i j}} & \text { jika } \mathrm{j} \text { adalah atribut keuntungan (benefit) } \\
\frac{\operatorname{Min}_{i j}}{x_{i j}} & \text { jika } \mathrm{j} \text { adalah atribut biay a (cost) }
\end{array}\right] .
$$


Pada persamaan 1 Rumus normalisasi menjelaskan rumus perhitungan untuk menjadi matriks dari nilai kriteria yang menentukan benefit atau cost.

Keterangan:

rij = Rating kinerja ternormalisasi

Max Xij = Nilai maksimum dari setiap baris dan kolom

Min Xij = Nilai minimum dari setiap baris dan

kolom

$\mathrm{Xij}=$ Baris dan kolom dari matriks

Benefit = Jika nilai terbesar adalah terbaik

Cost = Jika nilai terkecil adalah terbaik

a) Perhitungan Kriteria Absensi

Perhitungan Kriteria Absensi dari guru, dinilai dari penilaian rata-rata per sub kriteria. $\mathrm{R}$ ialah alternatif guru.

$$
\begin{aligned}
& \mathrm{R}_{11}=\frac{2}{5}=0,400 \\
& \mathrm{R}_{21}=\frac{5}{5}=1,000 \\
& \mathrm{R}_{31}=\frac{5}{5}=1,000 \\
& \mathrm{R}_{41}=\frac{5}{5}=1,000 \\
& \mathrm{R}_{51}=\frac{3}{5}=0,600
\end{aligned}
$$

Pada Perhitungan diatas, dicari nilai terbesar untuk pembagian. Karena dari kriteria tersebut, semua kriteria menghasilkan kategori benefit.

b) Perhitungan Pendagogik

Perhitungan Kriteria Pendagogik dari guru, dinilai dari penilaian rata-rata per sub kriteria. $\mathrm{R}$ ialah alternatif guru.

$$
\begin{aligned}
& \mathrm{R}_{12}=\frac{3,5}{4}=0,875 \\
& \mathrm{R}_{22}=\frac{3,4}{4}=0,850 \\
& \mathrm{R}_{32}=\frac{3,5}{4}=0,875 \\
& \mathrm{R}_{42}=\frac{4}{4}=1,000 \\
& \mathrm{R}_{52}=\frac{3,1}{4}=0,775
\end{aligned}
$$

Pada Perhitungan diatas, dicari nilai terbesar untuk pembagian. Karena dari kriteria tersebut, semua kriteria menghasilkan kategori benefit.

c) Perhitungan Kriteria Kepribadian

Perhitungan Kriteria Pendagogik dari guru, dinilai dari penilaian rata-rata per sub kriteria. $\mathrm{R}$ ialah alternatif guru.

$$
\begin{aligned}
& \mathrm{R}_{13}=\frac{3,3}{3,6}=0,917 \\
& \mathrm{R}_{23}=\frac{3,6}{3,6}=1,000 \\
& \mathrm{R}_{33}=\frac{3.3}{3,6}=0,917 \\
& \mathrm{R}_{43}=\frac{3.6}{3,6}=1,000
\end{aligned}
$$

$$
\mathrm{R}_{53}=\frac{3,6}{3,6}=1,000
$$

d) Perhitungan Kriteria Sosial

Perhitungan Kriteria Sosial dari guru, dinilai dari penilaian rata-rata per sub kriteria. $\mathrm{R}$ ialah alternatif guru.

$$
\begin{aligned}
& \mathrm{R}_{14}=\frac{3,5}{4}=0,875 \\
& \mathrm{R}_{24}=\frac{4}{4}=1,000 \\
& \mathrm{R}_{34}=\frac{3,5}{4}=0,875 \\
& \mathrm{R}_{44}=\frac{4}{4}=1,000 \\
& \mathrm{R}_{54}=\frac{4}{4}=1,000
\end{aligned}
$$

Pada Perhitungan diatas, dicari nilai terbesar untuk pembagian. Karena dari kriteria tersebut, semua kriteria menghasilkan kategori benefit.

e) Perhitungan Kriteria Profesional

Perhitungan Kriteria Profesional dari guru, dinilai dari penilaian rata-rata per sub kriteria. $\mathrm{R}$ ialah alternatif guru.

$$
\begin{aligned}
& \mathrm{R}_{15}=\frac{4}{4,5}=0,888 \\
& \mathrm{R}_{25}=\frac{4}{4,5}=0,888 \\
& \mathrm{R}_{35}=\frac{4,5}{4.5}=1,000 \\
& \mathrm{R}_{45}=\frac{3.5}{4.5}=0,777 \\
& \mathrm{R}_{55}=\frac{4.5}{4.5}=1,000
\end{aligned}
$$

Pada Perhitungan diatas, dicari nilai terbesar untuk pembagian. Karena dari kriteria tersebut, semua kriteria menghasilkan kategori benefit.

b. Hasil Normalisasi

Setelah normalisi, mendapatkan hasil untuk menghitung nilai akhir dari penilaian guru.

Tabel 6. Hasil Normalisasi

\begin{tabular}{|c|c|c|c|c|c|}
\hline \multirow{2}{*}{ Alternatif } & \multicolumn{5}{|c|}{ Kriteria } \\
\cline { 2 - 6 } & Absensi & Pedagogik & Kepribadian & Sosial & Profesional \\
\hline KM001 & 0,400 & 0,875 & 0,917 & 0,875 & 0,888 \\
\hline KM002 & 1,000 & 0,850 & 1,000 & 1,000 & 0,888 \\
\hline KM003 & 1,000 & 0,875 & 0,917 & 0,875 & 1,000 \\
\hline KM004 & 1,000 & 1,000 & 1,000 & 1,000 & 0,777 \\
\hline KM005 & 0,600 & 0,775 & 1,000 & 1,000 & 1,000 \\
\hline Bobot & $\mathbf{0 , 1}$ & $\mathbf{0 , 2}$ & $\mathbf{0 , 3}$ & $\mathbf{0 , 2}$ & $\mathbf{0 , 2}$ \\
\hline
\end{tabular}

Pada Tabel 6. Hasil normalisasi terdapat nilainilai dari kriteria yang kategorinya benefit.

Tahap selanjutnya adalah proses nilai bobot preferensi untuk setiap alternatif dengan rumus sebagai berikut:

$$
V_{i}=\sum_{j=1}^{n} w_{j} r_{i j}
$$


Berikut ini adalah perhitungan bobot prefrensi untuk hasil normalisasi per altenatif:

Dibawah ini perhitungan hasil normalisai, nilai tersebut dari nilai normalisasi per kriteria dan bobot.

a) KM001 (Adhika Puspitasari, S.Pd)

$=\{(0,400 \times 0,1)+(0,875 \times 0,2)+(0,917 \times 0,3)+$ $(0,875 \times 0,2)+(0,888 \times 0,2)\}$

$=(0,04+0,175+0,275+0,175+0,177)$

$=0,842$

Dari perhitungan tersebut akan menghasilkan nilai akhir untuk perhitungan penilaian guru terbaik.

Dibawah ini perhitungan hasil normalisai, nilai tersebut dari nilai normalisasi per kriteria dan bobot.

b) KM002 (Agni Dwi Elfahmi, S.Pd)

$=\{(1,000 \times 0,1)+(0,850 \times 0,2)+(1,000 \times 0,3)+$ $(1,000 \times 0,2)+(0,888 \times 0,2)\}$

$=(0,1+0,17+0,3+0,2+0,177)$

$=0,947$

Dari perhitungan tersebut akan menghasilkan nilai akhir untuk perhitungan penilaian guru terbaik.

Dibawah ini perhitungan hasil normalisai, nilai tersebut dari nilai normalisasi per kriteria dan bobot.

c) KM003 (Ana Saptini, S.Pd, M.M.)

$=\{(1,000 \times 0,1)+(0,875 \times 0,2)+(0,917 \times 0,3)+$

$(0,875 \times 0,2)+(1,0000 \times 0,2)\}$

$=(0,1+0,175+0,275+0,175+0,2)$

$=0,925$

Dari perhitungan tersebut akan menghasilkan nilai akhir untuk perhitungan penilaian guru terbaik.

Dibawah ini perhitungan hasil normalisai, nilai tersebut dari nilai normalisasi per kriteria dan bobot.

d) KM004 (Badriah El Qudsy, S.Pd)

$=\{(1,000 \times 0,1)+(1,000 \times 0,2)+(1,000 \times 0,3)+$

$(1,000 \times 0,2)+(0,777 \times 0,2)\}$

$=(0,1+0,2+0,3+0,2+0,155)$

$=0,955$

Dari perhitungan tersebut akan menghasilkan nilai akhir untuk perhitungan penilaian guru terbaik.

Dibawah ini perhitungan hasil normalisai, nilai tersebut dari nilai normalisasi per kriteria dan bobot.

e) KM005 (Ainor Kholis, S.PdI )

$=\{(0,600 \times 0,1)+(0,775 \times 0,2)+(1,000 \times 0,3)+$

$(1,000 \times 0,2)+(1,000 \times 0,2)\}$

$=(0,06+0,155+0,3+0,2+0,2)$

$=0,915$

Dari perhitungan tersebut akan menghasilkan nilai akhir untuk perhitungan penilaian guru terbaik.

Dari perhitungan bobot preferensi didapatkan hasil perankingan alternatif sebagai berikut:

Ranking $1=$ Badriah El Qudsy, S.Pd = 0,955

Ranking 2 = Agni Dwi Elfahmi, S.Pd $=0,947$

Ranking 3 = Ana Saptini, S.Pd, M.M. = 0,925
Ranking $4=$ Ainor Kholis, S.PdI $=0,915$

Ranking 5 = Adhika Puspitasari, S.Pd = 0,842

Sehingga disimpulkan berdasarkan perankingan diatas nilai tertinggi didapatkan oleh Badriah El Qudsy, S.Pd dan sekaligus direkomendasikan sebagai alternatif guru terbaik.

\subsection{Perancangan Database}

Entity Relationship Diagram (ERD)

Perancangan database disajikan dalam bentuk model data, Model ini dirancang untuk keperluan pengembangan Sistem Penunjang Keputusan. Sebuah Rancangan model data disajikan dalam bentuk Entity Relationship Diagram (ERD).

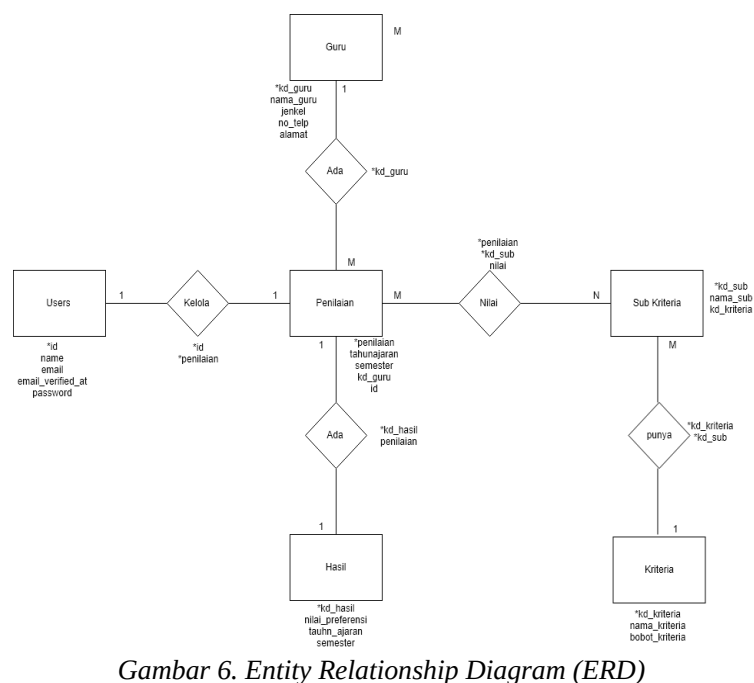

Pada Gambar 6. Entity Relationship Diagram (ERD) ialah database untuk sistem penunjang keputusan penilaian gurut terbaik.

\subsection{Rancangan Layar}

a. Struktur Tampilan Menu

Struktur tampilan menu sistem penunjang keputusan penilaian guru terbaik pada SD Islam Dian Didaktika Cinere.

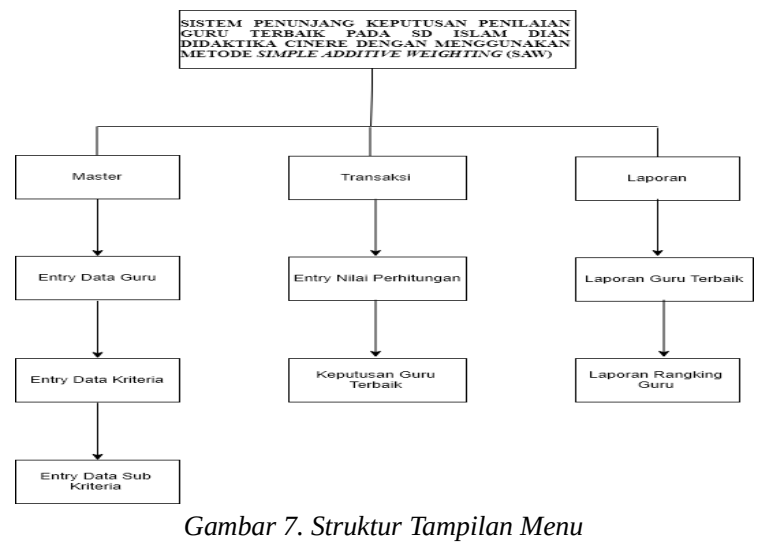


Pada Gambar 7. Struktur tampilan menu sistem penunjang keputusan penilaian guru terbaik terdapat maste, transaksi dan laporan.

\section{b. Entry Data Guru}

Dibawah ini ialah layar data guru SD Islam Dian Didaktika.

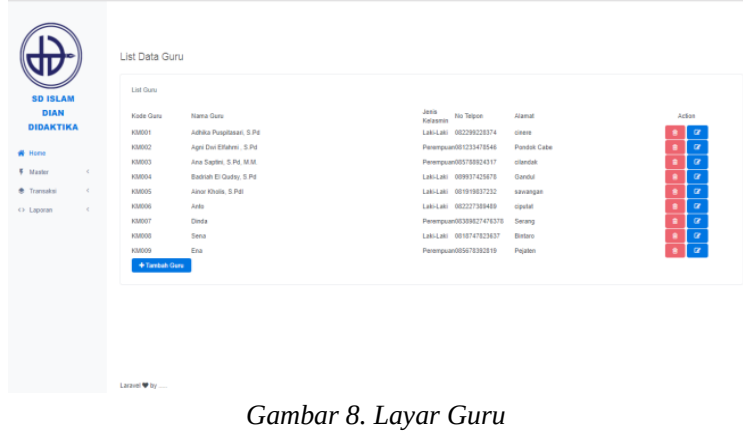

Pada gambar 8. layar guru ialah inputan untuk data guru penilaian guru terbaik.

\section{c. Entry Data Kriteria}

Dibawah ini layar data kriteria yang sudah ditentukan SD Islam Dian Didaktika.

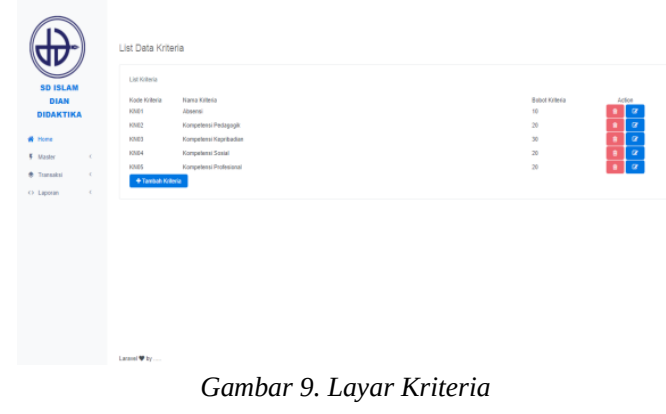

Pada gambar 9. layar kriteria ialah inputan untuk data guru penilaian guru terbaik.

\section{d. Entry Data Sub Kriteria}

Dibawah ini layar data sub kriteria yang sudah ditentukan SD Islam Dian Didaktika.

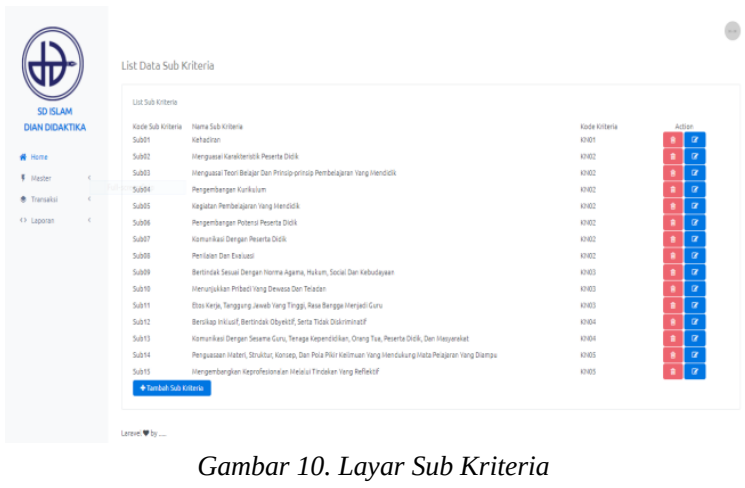

Pada gambar 10. layar sub kriteria ialah inputan untuk data sub kriteria penilaian guru terbaik.

e. Perhitungan

Dibawah ini layar perhitungan penilaian guru terbaik SD Islam Dian Didaktika.

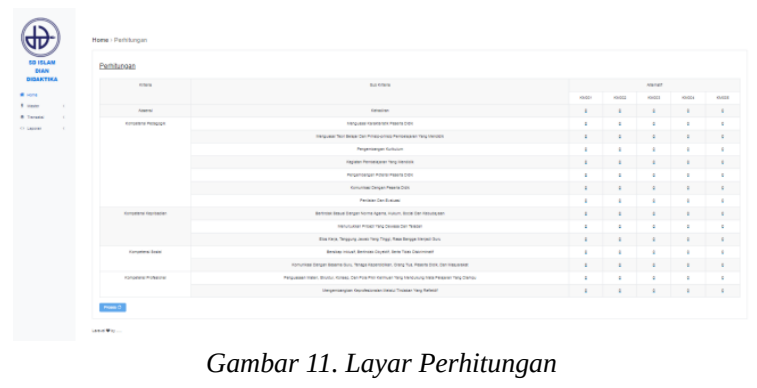

Pada gambar 11. layar perhitungan penilain guru terbaik yang sudah dinilai melalui proses pengamatan oleh tim personalia selaku tim penilaian.

f. Keputusan Guru Terbaik

Dibawah ini layar keputusan penilaian guru terbaik SD Islam Dian Didaktika.

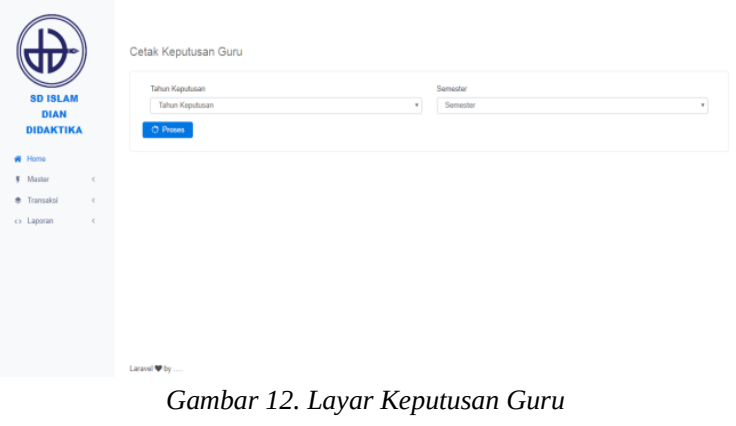

Pada gambar 12. layar keputusan guru, tim personalia selaku penilai memilih tahun ajaran dan semester untuk melihat penilaian guru yang ingin dicetak untuk memilih guru terbaik yang telah dinilai di rancangan perhitungan.

g. Rancangan Laporan

Dibawah layar laporan dari proses perhitungan penilaian guru terbaik SD Islam Dian Didaktika. 


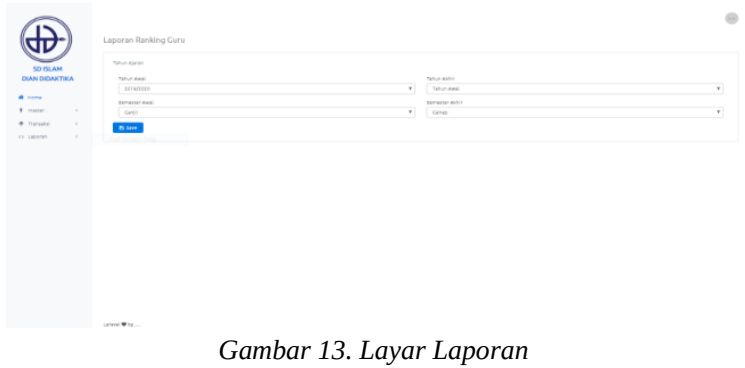

Pada gambar 13. layar laporan, tim personalia selaku penilai memilih tahun ajaran dan semester untuk melihat penilaian guru dan ranking untuk merekomendasikan menjadi guru terbaik.

\subsection{Cetakan Keluaran}

a. Cetakan layar keluaran guru terbaik terdapat hasil dari cetakan rancangan layar laporan guru terbiak.

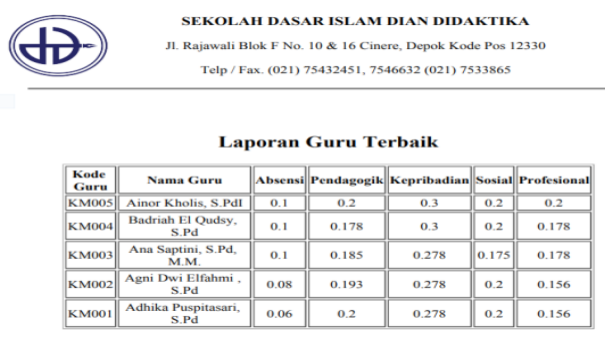

Gambar 14. Layar Keluaran

Pada gambar 14. layar keluaran laporan ialah hasil dari cetakan penilaian keseluruhan guru terbaik yang telah dihitung diperhitungan.

b. Cetakan layar keluaran ranking guru terdapat hasil dari cetakan rancangan layar laporan guru terbiak

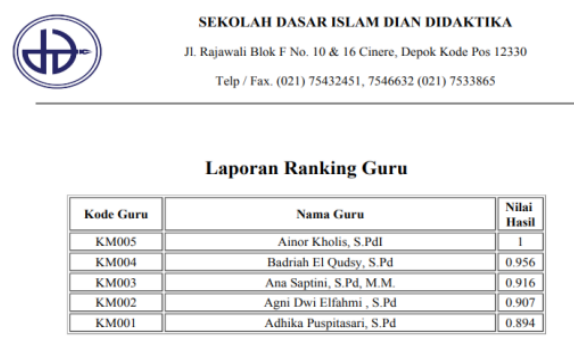

Gambar 15. Cetakan Layar LaporanRanking

Pada gambar 15. layar keluaran laporan ialah hasil dari cetakan penilaian keseluruhan guru terbaik yang telah dihitung diperhitungan.

\section{KESIMPULAN}

Berdasarkan apa yang telah dibuat, peneliti menarik kesimpulan bahwa dengan adanya sistem dapat mempermudah dan mempercepat dalam pengolahan data, perhitungan, dan pencetakan laporan dari hasil penilaian karena semuanya dilakukan didalam suatu sistem, sehingga dapat meminimalisir kesalahan dan mempercepat proses penilaian guru terbaik. Dan dengan adanya penyimpanan rekap data penilaian guru dengan database dapat membantu dan mempermudah dalam melihat rekap penilaian guru.

Oleh karena itu saran yang bisa diberikan yaitu, ketelitian dalam penginputan nilai perlu, agar memaksimalkan hasil keputusan dan user yang mengelola sistem tersebut perlu diberikan pelatihan agar mengoperasikan dengan lebih baik dan tidak terjadi kesalahan.

\section{DAFTAR PUSTAKA}

[1] Nawawi. 'Manajemen Sumber Daya Manusia', Jurnal Universitas Gadjah Mada, Vol. X No. 5. 2015

[2] Djamarah. 'Pengertian Kinerja Terhadap Guru'. Jurnal Pelita Ilmu Vol. IX No. 3. 2015

[3] Indrajani. Database Design. 1st edn. Jakarta: PT Elex Media Komputindo. 2017

[4] Nugroho Susanto, A. Jurus Jitu Membangun Bisnis Berkah Omset Milyaran. 1st edn. Yogyakarta: PT Vindra Sushantco Putra. 2015, Available at: https://bit.ly/2Ix4SJj.

[5] Abadi, S. dan Latifah, F. 'Decision Support System Penilaian Kinerja Karyawan Pada Perusahaan Menggunakan Metode Simple Additive Weighting', Jurnal TAM (Technology Acceptance Model), 6, 2016, pp. 37-43. 